\title{
Glucose screening within six months postpartum among Chinese mothers with a history of gestational diabetes mellitus: a prospective cohort study
}

Zhu-yun Liu', Juan-juan Zhao ${ }^{2}$, Ling-ling Gao ${ }^{2^{*}}$ and Alex Y. Wang ${ }^{3}$

\begin{abstract}
Background: Gestational diabetes mellitus (GDM) is a risk factor for diabetes mellitus. The 75-g, 2-h oral glucose tolerance test is recommended for mothers with a history of GDM to screen for diabetes in the postnatal period. The aim of this study was to investigate the rate of glucose screening within 6 months postpartum among Chinese mothers with a history of GDM, and to identify its predictors.

Methods: A prospective cohort study was conducted in a regional teaching hospital in Guangzhou, China, between July 2016 and June 2017. The participants were Chinese mothers $(n=237)$ who were diagnosed with GDM, were aged 18 years or older with no serious physical or mental disease and had not been diagnosed with type 1 or type 2 diabetes prior to their pregnancy. The revised Chinese version of the Champion's Health Belief Model Scale and social-demographic and perinatal characteristics factors were collected and used to predict postpartum glucose screening (yes or no). Adjust odds ratio (AOR) and $95 \%$ confidence interval $(95 \% \mathrm{Cl})$ were calculated.

Results: The mean age of the 237 mothers was 32.70 years (range from 22 to 44). Almost half of the mothers (45. $6 \%$ ) were college graduates or higher. Chinese mothers reported a high level of perceived benefits, self-efficacy, and health motivation towards postpartum glucose screening, with a mean score above 3.5.

Chinese mothers were more likely to undertake postpartum glucose screening if they were a first-time mother [AOR 2.618 (95\% Cl: 1.398-4.901)], had a high perceived susceptibility score [AOR 2.173 (95\% Cl: 1.076-4.389)], a high perceived seriousness score [AOR 1.988 (95\%Cl: 1.020-3.875)] and high perceived benefits score [AOR 2.978 (95\%Cl: 1.540-5.759)].

Conclusion: The results of this study will lead to better identification of mothers with a history of GDM who may not screen for postpartum glucose abnormality. Health care professionals should be cognizant of issues that may affect postpartum glucose screening among mothers with a history of GDM, including parity, perceived susceptibility, perceived seriousness and perceived benefits.
\end{abstract}

Keywords: Diabetes, Gestational, Health beliefs, Postpartum glucose screening

\footnotetext{
* Correspondence: gaoll@mail.sysu.edu.cn

${ }^{2}$ School of Nursing, Sun Yat-sen University, 74\#, Zhongshan Road II,

Guangzhou 510089, China

Full list of author information is available at the end of the article
}

(c) The Author(s). 2019 Open Access This article is distributed under the terms of the Creative Commons Attribution 4.0 International License (http://creativecommons.org/licenses/by/4.0/), which permits unrestricted use, distribution, and reproduction in any medium, provided you give appropriate credit to the original author(s) and the source, provide a link to the Creative Commons license, and indicate if changes were made. The Creative Commons Public Domain Dedication waiver (http://creativecommons.org/publicdomain/zero/1.0/) applies to the data made available in this article, unless otherwise stated. 


\section{Background}

Diabetes mellitus is a complex chronic condition with serious physical, psychological, and clinical complications for the individuals affected [1]. Gestational diabetes mellitus (GDM) is a risk factor for diabetes mellitus. Mothers with a history of GDM are 7 times more likely to develop type 2 diabetes mellitus later in life than those without a history of GDM [2]. In fact, up to 70\% of mothers with a history of GDM will develop type 2 diabetes mellitus if there is no intervention [3]. In mainland China, GDM has become one of the most common complications during pregnancy. A recent survey of 15,194 Chinese pregnant women found that $19.7 \%$ of them were diagnosed with GDM, which was higher than the average morbidity worldwide [4].

Given the impact of prolonged undetected hyperglycaemia, prevention and early diagnosis of diabetes is cost-effective and important for public health [5-7]. It is recommended that all mothers with a history of GDM should screen for glucose in the postpartum period [8, 9]. This can help to detect glucose abnormality and then provide early preventive interventions. Many mothers diagnosed with GDM however, do not undergo blood glucose screening within the postnatal period [10-12]. One report indicated that only $13.1 \%$ Chinese mothers (282 out of 2152) with a history of GDM were screened for blood glucose in the postnatal period [10].

A number of international studies have suggested that screening behaviour can be predicted by health beliefs [13-15]. According to the Health Belief Model, health beliefs refer to subjective feelings and cognition when forming healthy behaviours. The Health Belief Model consists of six constructs: perceived susceptibility, perceived seriousness, perceived benefits, perceived barriers, cues to action and self-efficacy [16]. The Health Belief Model proposes that people must believe that, even in the absence of any symptom, the disease may exist. When people find themselves at risk of the disease (perceived susceptibility), realize that the disease has serious potential consequences (perceived seriousness), believe that barriers of that behaviour (perceived barriers) are less than the obtained benefits (perceived benefits), and believe that they are able to undertake health behaviour activities (self-efficacy), they are more likely to accomplish screening behaviour [17].

Apart from health beliefs, the literature shows that other factors are associated with postpartum glucose screening. These include socio-demographic characteristics such as age, race, parity, income, education, pre-pregnancy weight or body mass index (BMI) [18-20] and perinatal characteristics which include insulin use during pregnancy, medication use during pregnancy, postpartum visits, and gestational weight gain $[11,19,21]$.
It is important to identify a set of factors associated with postpartum glucose screening in mothers with a history of GDM. Once identified, effective counselling and promotion policies can be therefore implemented to improve rates of postpartum glucose screening. However, limited evidence is available on the association between postpartum glucose screening and health beliefs and other factors among mothers with a history of GDM. This study aims to investigate the rate of the postpartum glucose screening and identify its predictors among Chinese mothers with a history of GDM.

\section{Methods}

Study design

A prospective cohort study was conducted.

\section{Settings and participants}

The study was carried out in Guangzhou, the capital of Guangdong Province located in southeast China. Guangzhou is classed as a first-tier city with a population of around 16 million. More than half of the employed women have received a tertiary education with 82.3\% having a higher qualification in some Districts of Guangzhou [22].

One leading hospital in Guangzhou was selected for this study. The incidence rate of GDM in the study hospital was $17 \%$ from 2013 to 2016, which is similar to the average incidence of GDM in China in 2010 which was $17.5 \%$ [23]. The participating mothers were recruited from 2106 mothers who gave birth between July and December 2016.

GDM is diagnosed based on the criteria of the International Association of Diabetes and Pregnancy Study Group (IADPSG), recommended by the Chinese Medical Association [9]. The IADPSG criteria define GDM as a fasting blood glucose (FPG) $>5.1 \mathrm{mmol} / \mathrm{l}$, a 1-h glucose level $>10.0 \mathrm{mmol} / \mathrm{l}$ or a 2 -h glucose level $>8.5 \mathrm{mmol} / \mathrm{l}$. [9]. The mothers were recruited from the postnatal wards of the study hospital. Mothers were eligible if they were diagnosed with GDM, aged 18 years or older, had given birth to a term ( $>36$ complete weeks of gestation) singleton, with no serious physical or mental disease and had not been diagnosed with type 1 or type 2 diabetes prior to their pregnancy. Mothers were excluded if they had multiple deliveries, had serious physical or mental health conditions, had re-conceived within 6 months postpartum or were diagnosed with type 1or type 2 diabetes mellitus prior to pregnancy.

\section{Study factors}

A revised Chinese version of the Champion's Health Belief Model Scale (RC-CHBMS) was used to measure health beliefs. The original Chinese version of the Champion's Health Belief Model Scale was a scale 
adapted from Champion [24, 25] to measure beliefs related to liver cancer screening [26]. It was subsequently revised to measure beliefs related to diabetes and postpartum screening for diabetes. The RC-CHBMS has been validated in Chinese women with a history of GDM. Reported internal consistency for the scale was 0.833; the six subscales' Cronbach's alpha coefficients ranged from 0.773 (motivation) to 0.806 (perceived benefits) [27].

The RC-CHBMS is a 33-item instrument consisting of 6 subscales: perceived susceptibility ( 5 items), perceived seriousness (6 items), perceived benefits ( 6 items), perceived barriers ( 6 items), health motivation ( 5 items) and self-efficacy (5 items). Each item was rated on a five-point Likert scale ranging from "strongly disagree" (1 point) to "strongly agree" (5 points). A higher ranking on the Likert scale indicates a stronger agreement with the health beliefs (for example, a higher benefit score indicated perception of greater benefits and a higher barrier score indicated a greater perception of barriers). All subscales were positively related to postpartum screening for diabetes, except for barriers which were negatively associated.

A self-designed social-demographic data sheet was used to collect data on maternal age, marital status, education, employment and family income, family history of diabetes and pre-pregnancy body mass index (BMI). A number of perinatal characteristics were collected, including parity, gestational age at the diagnosis of GDM, plasma glucose of OGTT during pregnancy, insulin therapy during pregnancy, gestational weight gain, glucose control during pregnancy, mode of delivery, infant feeding method and childcare assistance.

After giving informed written consent, mothers were asked to complete the RC-CHBMS and self-designed social-demographic data sheet. Both RC-CHBMS and social-demographic data sheet were collected within 4 days following the birth. Data on perinatal characteristics were collected from the mothers' medical record.

In mainland China, the recommended ranges for blood glucose control for pregnant women with GDM are as follows: pre-prandial and fasting plasma glucose between 3.3 and $5.6 \mathrm{mmol} / \mathrm{l}(60-99 \mathrm{mg} / \mathrm{dl})$ and a 2 -h post-prandial plasma glucose between 5.6 and $7.1 \mathrm{mmol} / \mathrm{l}(100-129 \mathrm{mg} /$ dl). At each prenatal visit, the obstetrician checks the self-monitoring record of every pregnant women with GDM. If more than $70 \%$ of the self-monitored blood glucose results reached the recommended level, blood glucose control was considered acceptable. Blood glucose control was considered good if more than $90 \%$ reached the recommended level. If the pregnant women did not meet the recommended blood glucose targets, an insulin injection would be offered. If the insulin was rejected the women would be offered oral hypoglycaemics.

\section{Outcome measures and follow up}

In this study, the postpartum glucose screening refers to 75-g, 2-h oral glucose tolerance test (OGTT) within 6 months postpartum based on the guidelines of the American Diabetes Association and the Chinese Medical Association [8, 9]. The World Health Organization [28] criteria for diabetes, impaired glucose tolerance and impaired fasting glucose were used to assess the postpartum glucose screening result: for diabetes: 2-h plasma glucose of OGTT $\geq 11.1 \mathrm{mmol} / \mathrm{l}$ or fasting plasma glucose $\geq 7.0 \mathrm{mmol} / \mathrm{l}$; for impaired glucose tolerance: 2 -h plasma glucose between 7.8 and $11.0 \mathrm{mmol} / \mathrm{l}$; for impaired fasting glucose: fasting plasma glucose between 6.1 and $6.9 \mathrm{mmol} / \mathrm{l}$.

An online postpartum glucose screening data sheet was used to collect the screening behaviour. The questions on the online postpartum glucose screening data sheet included asking if a postpartum glucose screening had been undertaken within 6 months postpartum (Yes or No), the name of the hospital and the date of the screening, and the methods used to detect glucose abnormality. Mothers were reminded to complete the data sheet by a mobile-phone message. If the mother did not reply, a follow-up phone call was made within 2 weeks. If a mother had the postpartum glucose screening in the study hospital, the results were retrieved from her medical record. If screening was done at other hospitals or clinics, the results were obtained from the mother.

\section{Statistical analysis}

Descriptive statistics were used to present demographic and perinatal characteristics and the health beliefs. Some continuous variables such as age and health beliefs were categorised/dichotomised using clinical reference values or median values [29]. The mothers who had scores higher than the median on the 6 subscales were classified as having high level of health beliefs. Differences in rate of postpartum glucose screening among groups with different level of health beliefs, socio-demographic and perinatal characteristics were compared using the chi-squared test. Variables with $p<0.1$ in the above tests were input into the multivariable logistic regression model to determine the predictors of the postpartum glucose screening. Maternal age and BMI were adjusted in multivariable analyses. Odds ratio (OR), adjusted odds ratio (AOR) and 95\% confidence interval $(95 \% \mathrm{CI})$ were calculated. Data analysis was performed using SPSS 22.0 for Windows (SPSS Inc., Chicago, IL, USA).

\section{Results}

Demographic and perinatal characteristics

During the recruitment period, there were 357 mothers whose pregnancy was complicated with GDM. Of these, 294 met inclusion criteria. Twenty-six mothers $(8.8 \%)$ 
refused to participate, 31 (10.5\%) were lost to follow-up or withdrew from the study. At 6 months follow-up, 237 mothers finished the questionnaires (Fig. 1). There were no differences in socio-demographic characteristics between the mothers who completed the study and those who did not.

Table 1 presents the demographic characteristics of the mothers. The mean age of the mothers was $32.70 \mathrm{y}(\mathrm{SD}=$ 4.59 , range $=22-44)$. Almost half of the mothers $(45.6 \%)$ were college graduates or higher. More than one third of the mothers $(35.9 \%)$ had a monthly household income $>¥$ 9000 (US\$1327), which was above the average monthly household income in Guangzhou [30] (Additional file 1).

Table 2 presents the perinatal characteristics of mothers. In this study, half of the mothers (52.7\%) had good glycaemic control during their pregnancy. However, only 7 mothers used insulin and 35 used oral agents to control blood glucose during pregnancy. Almost one fourth of the mothers (24.9\%) had a family history of diabetes. More than half of the mothers (66.7\%) exclusively breastfed their babies within the 6-month postpartum period. Childcare assistance was present for $62.9 \%$ of mothers.

\section{Health beliefs}

Table 3 presents the mean item score and the median score of the 6 subscales of the RC-CHBMS in descending order. The mothers had a high level of perceived benefits, self-efficacy and health motivation with the mean item score above 3.5 on these three subscale. Less than half of the mothers had a high level of perceived benefits (49.8\%); self-efficacy (40.9\%); health motivation (43.5\%) and perceived barriers (48.9\%). Only one third of the mothers $(33.8 \%)$ had a high level of perceived seriousness of diabetes mellitus; while two thirds of the mothers had a high level of perceived susceptibility.

\section{Postpartum glucose screening}

Of the 237 mothers, 91 had postpartum glucose screening, which presents a postpartum glucose screening rate

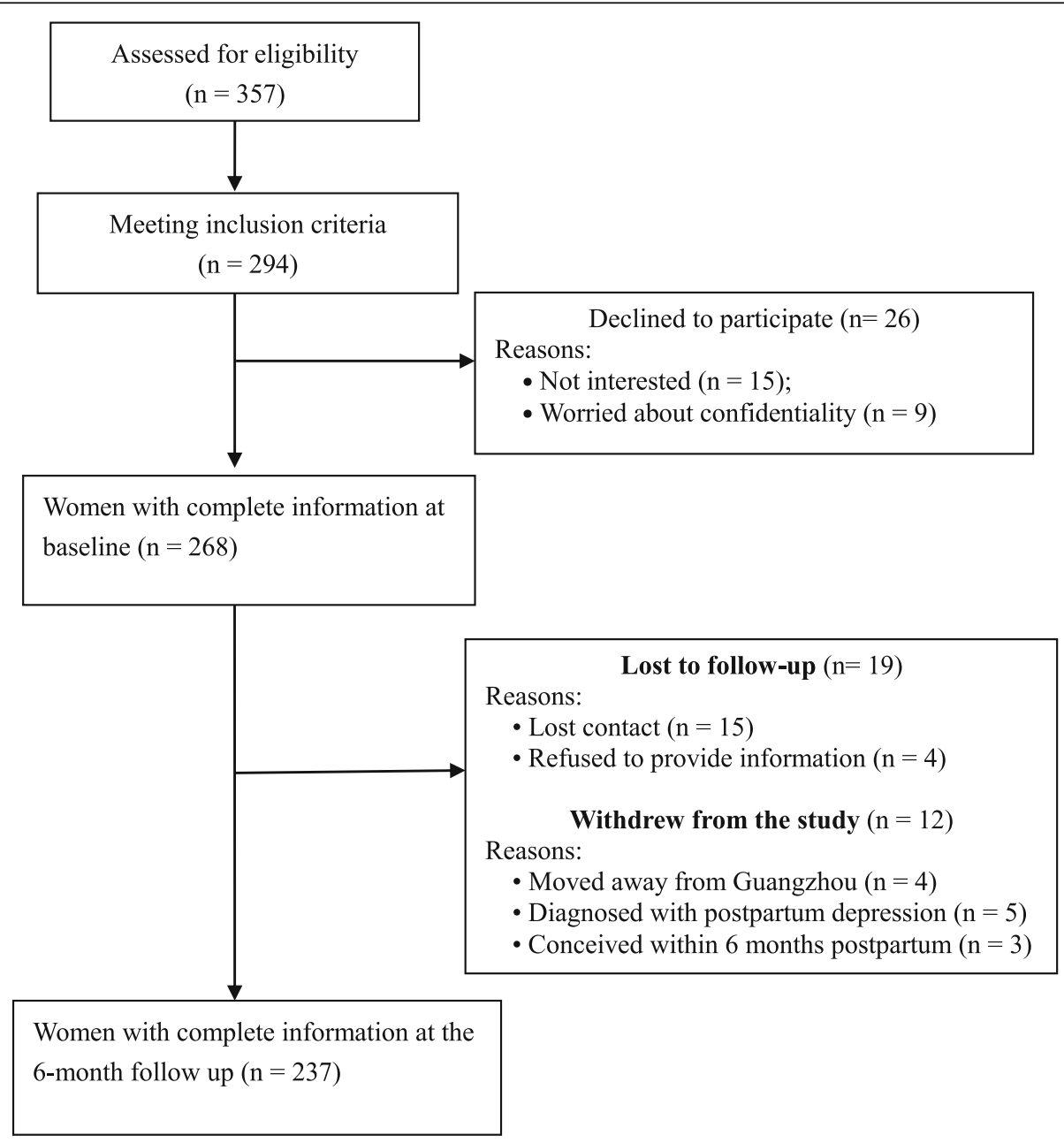

Fig. 1 Flowchart of recruitment and loss to follow-up for the study 
Table 1 Demographic characteristics of the mothers $(n=237)$

\begin{tabular}{|c|c|c|}
\hline Characteristics & $\mathrm{n}$ & $\%$ \\
\hline \multicolumn{3}{|l|}{ Ages (years) } \\
\hline$<30$ & 62 & 26.2 \\
\hline $30-34$ & 95 & 40.1 \\
\hline$\geq 35$ & 80 & 33.8 \\
\hline \multicolumn{3}{|l|}{ Education } \\
\hline Senior high school or less & 53 & 22.4 \\
\hline Junior college & 76 & 32.1 \\
\hline College graduate & 68 & 28.7 \\
\hline Graduate degree or above & 40 & 16.9 \\
\hline \multicolumn{3}{|l|}{ Monthly family income } \\
\hline$<¥ 5000$ (about US\$737) & 37 & 15.6 \\
\hline$¥ 5000-¥ 9000$ (about US\$737-US\$1327) & 115 & 48.5 \\
\hline > ¥9000 (aboutUS\$1327) & 85 & 35.9 \\
\hline \multicolumn{3}{|l|}{ Family history of diabetes } \\
\hline No & 164 & 69.2 \\
\hline Yes & 59 & 24.9 \\
\hline Not known & 14 & 5.9 \\
\hline \multicolumn{3}{|l|}{ Pre-pregnancy BMI (kg/m2) } \\
\hline$<18.5$ & 38 & 16.0 \\
\hline $18.5-24.9$ & 165 & 69.6 \\
\hline$\geq 25.0$ & 34 & 14.3 \\
\hline
\end{tabular}

of $38.4 \%$. Of the 91 mothers, $3(3.3 \%)$ were classified with impaired fasting glucose, $24(26.4 \%)$ with impaired glucose tolerance and 1 (1.1\%) with diabetes. In addition, $24.5 \%$ (58 of the 237) mothers reported that they had monitored their finger stick capillary blood glucose irregularly at home.

Mothers were more likely to have postpartum glucose screening if they were first-time mothers [OR 2.153, 95\% CI $(1.257,3.687)]$, or they had a family history of diabetes [OR 2.320, 95\% CI (1.266, 4.250)] (Table 4). Mothers with high level of perceived benefits [OR 4.772, 95\% CI $(2.695,8.451)]$, high level of perceived seriousness [OR 3.102, 95\% CI $(1.773,5.430)]$, or high level of perceived susceptibility [OR 3.550, 95\% CI (1.962, 6.422)] were more likely to undertake postpartum glucose screening. Blood glucose management during pregnancy was not related to postpartum glucose screening.

Variables that had significant correlation with postpartum glucose screening were retained in the logistic regression model. The best-fit regression model revealed 4 variables predicting postpartum glucose screening, including first-time mother [OR 2.618 (95\% CI: 1.398-4.901)], high perceived susceptibility score [OR 2.173 (95\% CI: 1.076-4.389)], high perceived seriousness score [OR 1.988 (95\%CI: 1.020-3.875)] and high perceived benefits score [OR 2.978 (95\%CI: 1.540-5.759)] (Table 5).
Table 2 Perinatal characteristics of the mothers $(n=237)$

\begin{tabular}{lll}
\hline Characteristics & $\mathrm{n}$ & $\%$ \\
\hline Parity & & \\
1 & 93 & 39.2 \\
$\geq 2$ & 144 & 60.8
\end{tabular}

Gestational age when diagnosed with gestational diabetes mellitus (weeks)

$\begin{array}{lll}<24 & 14 & 5.9 \\ 24-28 & 200 & 84.4 \\ >28 & 23 & 9.7\end{array}$

Gestational diabetes mellitus diagnostic OGTT glucose (mmol/l) (Mean \pm S.D.)

$\begin{array}{ll}\text { Fasting plasma glucose } & 4.59 \pm 0.65 \\ \text { 1-h plasma glucose } & 9.90 \pm 1.60 \\ \text { 2-h plasma glucose } & 9.07 \pm 1.40\end{array}$

Management of gestational diabetes mellitus

$\begin{array}{lll}\text { Diet or physical activity } & 195 & 82.3\end{array}$

$\begin{array}{lll}\text { Oral agents } & 35 & 14.8\end{array}$

$\begin{array}{lll}\text { Insulin injection } & 7 & 3.0\end{array}$

Blood glucose control during pregnancy

$\begin{array}{lll}\text { Acceptable or good } & 125 & 52.7\end{array}$

$\begin{array}{lll}\text { Not good } & 70 & 29.5\end{array}$

$\begin{array}{lll}\text { Data were unavailable } & 42 & 17.7\end{array}$

Gestational weight gain

Within the range of the recommended $\quad 91 \quad 38.4$

$\begin{array}{lll}\text { More than the recommended } & 24 & 10.1\end{array}$

Mode of delivery

$\begin{array}{lll}\text { Spontaneous vaginal birth or vacuum } & 146 & 61.6\end{array}$

Caesarean section

$91 \quad 38.4$

Infant feeding method

Exclusive breastfeeding

Mixed feeding

$158 \quad 66.7$

$69 \quad 29.1$

Formula feeding

$10 \quad 4.2$

Having someone help with childcare

\begin{tabular}{lll} 
Yes & 149 & 62.9 \\
No & 88 & 37.1 \\
\hline
\end{tabular}

OGTT Oral glucose tolerance test

\section{Discussion}

According to our knowledge, this is the first study to explore the predictors of postpartum glucose screening among Chinese mothers with a history of GDM based on the Health Belief Model. The findings of the present study confirm the evidence that mothers with a history of GDM have a high risk for abnormal glucose regulation $[2,4,31]$. Therefore, all mothers with a history of GDM should have postpartum glucose screening. However, in the present study, only 91 (38.4\%) of 237 
Table 3 The mothers' scores on the subscales of the RC-CHBMS $(n=237)$

\begin{tabular}{lllll}
\hline Variables & Mean \pm SD & Median & Number and percent > median (High) & Number and percent $\leq$ median (Low) \\
\hline Perceived benefits & $3.83 \pm 0.29$ & 3.83 & $118(49.8 \%)$ & $119(50.2 \%)$ \\
Self-efficacy & $3.75 \pm 0.36$ & 3.60 & $97(40.9 \%)$ & $140(59.1 \%)$ \\
Health motivation & $3.68 \pm 0.32$ & 3.80 & $103(43.5 \%)$ & $134(56.5 \%)$ \\
Perceived seriousness & $2.75 \pm 0.37$ & 2.83 & $80(33.8 \%)$ & $157(66.2 \%)$ \\
Perceived susceptibility & $2.63 \pm 0.49$ & 2.60 & $144(60.8 \%)$ & $93(39.2 \%)$ \\
Perceived barriers & $1.73 \pm 0.35$ & 1.67 & $116(48.9 \%)$ & $121(51.1 \%)$ \\
\hline
\end{tabular}

Table 4 Differences in rates of postpartum glucose screening between the mothers with high level of health beliefs and low level of health beliefs; and among the various socio-demographic and perinatal sub-groups $(n=237)$

\begin{tabular}{|c|c|c|c|}
\hline \multirow[t]{2}{*}{ Characteristics } & \multicolumn{2}{|c|}{ Postpartum Glucose screening } & \multirow[b]{2}{*}{ OR $(95 \% C l)$} \\
\hline & $\begin{array}{l}\text { Yes } \\
(n=91)\end{array}$ & $\begin{array}{l}\text { No } \\
(n=146)\end{array}$ & \\
\hline \multicolumn{4}{|l|}{ Parity } \\
\hline 1 & $46(49.5)$ & $47(50.5)$ & $2.153(1.257,3.687)$ \\
\hline$\geq 2$ & $45(31.2)$ & 99 (68.8) & Ref. \\
\hline \multicolumn{4}{|l|}{ Family history of diabetes } \\
\hline Yes & $33(55.9)$ & $26(44.1)$ & $2.320(1.266,4.250)$ \\
\hline No & $58(35.4)$ & $106(64.6)$ & Ref. \\
\hline Not known & $0(0.0)$ & $14(100.0)$ & 0.000 \\
\hline \multicolumn{4}{|l|}{ Mode of delivery } \\
\hline Spontaneous vaginal birth or vacuum & $63(43.2)$ & $83(56.8)$ & $1.708(0.983,2.968)^{a}$ \\
\hline Caesarean section & $28(30.8)$ & $63(69.2)$ & Ref. \\
\hline \multicolumn{4}{|l|}{ Having someone help with childcare } \\
\hline Yes & $64(43.0)$ & $85(57.0)$ & $1.701(0.974,2.970)^{a}$ \\
\hline No & $27(20.7)$ & $61(69.3)$ & Ref. \\
\hline \multicolumn{4}{|l|}{ Perceived benefits } \\
\hline Low & $25(21.0)$ & $94(79.0)$ & Ref. \\
\hline High & $66(55.9)$ & $52(44.1)$ & $4.772(2.695,8.451)$ \\
\hline \multicolumn{4}{|l|}{ Self-efficacy } \\
\hline Low & $52(37.1)$ & $88(62.9)$ & Ref. \\
\hline High & $39(40.2)$ & $58(59.8)$ & $1.138(0.669,1.936)$ \\
\hline \multicolumn{4}{|l|}{ Health motivation } \\
\hline Low & $46(34.3)$ & $88(65.7)$ & Ref. \\
\hline High & 45 (43.7) & $58(56.3)$ & $1.484(0.875,2.517)$ \\
\hline \multicolumn{4}{|l|}{ Perceived seriousness } \\
\hline Low & $46(29.3)$ & $111(70.7)$ & Ref. \\
\hline High & $45(56.2)$ & $35(43.8)$ & $3.102(1.773,5.430)$ \\
\hline \multicolumn{4}{|l|}{ Perceived susceptibility } \\
\hline Low & $20(21.5)$ & $73(78.5)$ & Ref. \\
\hline High & $71(49.3)$ & $73(50.7)$ & $3.550(1.962,6.422)$ \\
\hline \multicolumn{4}{|l|}{ Perceived barriers } \\
\hline Low & $51(42.1)$ & 70 (57.9) & $1.384(0.818,2.343)$ \\
\hline High & $40(34.5)$ & $76(65.5)$ & Ref. \\
\hline
\end{tabular}


Table 5 Predictors of postpartum glucose screening within 6 months postpartum among Chinese mothers with a history of gestational diabetes mellitus $(n=237)$

\begin{tabular}{|c|c|c|c|c|c|c|}
\hline \multirow[t]{2}{*}{ Variables } & \multirow[t]{2}{*}{$B$} & \multirow[t]{2}{*}{ wald } & \multirow[t]{2}{*}{$p$} & \multirow{2}{*}{$\begin{array}{l}\text { Adjusted } \\
\text { OR }\end{array}$} & \multicolumn{2}{|l|}{$95 \% \mathrm{Cl}$} \\
\hline & & & & & Lower & Uppe \\
\hline \multicolumn{7}{|l|}{ Parity $^{a}$} \\
\hline 1 & 0.962 & 9.043 & $0.003^{* *}$ & 2.618 & 1.398 & 4.901 \\
\hline$\geq 2$ & Reference & & & & & \\
\hline Perceived susceptibility & 0.776 & 4.678 & $0.031^{*}$ & 2.173 & 1.076 & 4.389 \\
\hline Perceived seriousness & 0.687 & 4.077 & $0.043^{*}$ & 1.988 & 1.020 & 3.875 \\
\hline Perceived benefits & 1.091 & 10.517 & $0.001^{* *}$ & 2.978 & 1.540 & 5.759 \\
\hline
\end{tabular}

Adjusted for maternal age, pre-pregnancy body mass index, family history of diabetes, mode of delivery, childcare, perceived susceptibility, perceived seriousness and perceived benefits

a Parity: 1 = primipara, $\geq 2$ = multipara

$p<0.05,{ }^{* *} p<0.01$

mothers underwent this screening within 6 months postpartum, which was lower than the rates from Japan and Singapore. Kugishima et al. [11] reported that $65.7 \%$ of Japanese mothers with a history of GDM underwent postpartum glucose screening within 6 to 8 weeks postpartum. Suan [20] reported that $81.9 \%$ of Singaporean mothers with a history of GDM performed postpartum glucose screening within 6 to 8 weeks postpartum.

The lower rate of postpartum glucose screening in the present study may be related to the fact that mothers with a history of GDM were not advised to undertake postpartum glucose screening during pregnancy and were also not reminded to do so after discharge from the hospital. Currently, in mainland China healthcare professionals tend to assume that GDM disappears after delivery. Whilst occupied with caring for the baby they neglect to inform the pregnant women to screen for blood glucose abnormality after the birth [10]. It was only when a mother with GDM remained in the hospital after birth, that postpartum screening for diabetes by an obstetric nurse in the postnatal ward was recommended. Following discharge from hospital community nurses visited mothers with GDM twice within the first month postpartum, focusing on breastfeeding and the mothers' physical recovery. Community nurses are not asked to remind these mothers to screen for diabetes as part of standard care [32].

Chang et al. [10] suggests that a reminder from health professionals is a key reason mothers with a history of GDM undertake postpartum glucose screening. A Cochrane literature review found that a reminder system for mothers with a history of GDM could increase the rate of postpartum glucose screening [33]. The findings of the present study indicate that there is an urgent need for postnatal healthcare professionals to remind mothers with a history of GDM to undertake postpartum glucose screening. A reminder system incorporating alerts into the mothers' electronic medical records could be established, along with short text messages, emails or telephone calls as reminders.
Interestingly, there were $58(24.5 \%)$ mothers with a history of GDM who monitored their finger stick capillary blood glucose irregularly by themselves. The finger test is however affected by temperature, humidity, operating practice and is not recommended to detect impaired fasting plasma and impaired glucose tolerance $[34,35]$. The OGTT is more sensitive at $100 \%$ compared with $67 \%$ for the fasting plasma glucose test [34]. Both the Chinese Medical Association [9] and American Diabetes Association [8] recommend the OGTT as the standard method of postpartum screening for diabetes. Considering that the mothers in the present study had a high level of health motivation and perceived less barriers to diabetes screening, one explanation for this finding may be due to mothers' lack of knowledge about the OGTT as the standard method of screening for diabetes. The findings of the present study suggested that healthcare professionals should not only remind the mothers to have postpartum glucose screening, but should also inform them that the OGTT is the standard method used to screen for glucose abnormality in the postpartum period.

The present study also found that parity predicted a woman's motivation to attend for postpartum glucose screening. First-time mothers were more likely to screen for glucose abnormality than those who had more than one child. This was consistent with previous studies where mothers who had more children were less likely to screen for glucose abnormality in the postpartum period [19, 31, 35]. Mothers with only one baby have relatively more available time for postpartum glucose screening than those who have more than one child which may account for this [36, 37].

Concerning the Health Belief Model, mothers with a history of GDM who perceived higher susceptibility to diabetes, perceived seriousness of diabetes and higher benefits of postpartum screening for diabetes were more likely to undertake postpartum glucose screening. This finding is consistent with the Health Belief Model [15] and studies 
on breast cancer screening [38]. Chang et al. [10] further indicated that a woman's belief that GDM would disappear after delivery was the second highest occurring reason for not performing postpartum glucose screening.

Mothers with a history of GDM have a moderate level of perceived susceptibility and perceived seriousness to diabetes and may not realize the risks subsequent diabetes. This may be another reason why many mothers with a history of GDM in the present study did not undertake postpartum glucose screening. This finding was consistent with a previous study, in which $74 \%$ of Australian mothers with a history of GDM did not perceive themselves at high or very high risk for developing diabetes in the future [39]. The findings of the present study suggested that an education program with a strong focus on perceived susceptibility and perceived seriousness to diabetes and the benefits of postpartum glucose screening may improve the uptake of such screening among the mothers with a history of GDM.

In relation to the management of their GDM, the present study found that only a small percent of pregnant women managed their blood glucose by insulin injection or oral medicine. Almost one third of the mothers did not effectively manage blood glucose during pregnancy. Only $3 \%$ of the mothers $(n=7)$ managed their blood glucose through the injection of insulin and $14.8 \%(n=35)$ by oral medicine. This may be because most Chinese pregnant women with GDM are resistant when treatment with insulin injection or oral agents is advised [40]. Insulin injection is perceived as inconvenient and women fear the side effects of oral agents on the foetus. Moreover, some of them may mistakenly believe that they have to rely on insulin on an ongoing basis once it has been used initially [40]. The findings of the present study are consistent with a previous study which suggested that health care professionals should put more effort into helping pregnant women with a history of GDM to understand how to manage GDM correctly, especially regarding insulin injection and oral medicine [41].

This study had some limitations. The study was conducted in one hospital. The majority of mothers were middle class women with a high-level of education [30]. Our findings may not be transferable to other settings or to women from a different social class, with lower levels of education or to rural women.

\section{Conclusion}

This study has significant clinical utility for health care professionals working with Chinese mothers with a history of GDM. To identify mothers who may not undergo postpartum glucose screening, health care professionals are advised to assess a mother's parity, health beliefs in relation to perceived susceptibility, perceived seriousness and perceived benefits. Health care professionals could develop strategies following assessment to encourage these mothers to undergo postpartum glucose screening. These strategies for example could be establishing a reminder system and providing education focused on the risk and seriousness of GDM for diabetes and the benefits of postpartum glucose screening.

\section{Additional file}

Additional file 1: The socio-demographic data sheet of the participants. This data sheet includes the socio-demographic information of all the participants. (SAV $3 \mathrm{~kb}$ )

\section{Abbreviations}

BMI: Body Mass Index; GDM: Gestational diabetes mellitus; OGTT: Oral glucose tolerance test

Acknowledgements

We would like to thank all the mothers who participated in this study.

Funding

This research did not receive any specific grant from funding agencies in the public, commercial or not-for-profit sectors.

\section{Availability of data and materials}

The dataset analysed during the current study is not publicly available because consent was not been obtained from the study participants for this. Deidentified data may be made available from the corresponding author on reasonable request, subject to permission from the relevant ethics committees at the hospital and university.

\section{Authors' contributions}

ZYL and LLG were responsible for the study conception and design; and were responsible for the drafting of the manuscript. JJZ helped in drafting the manuscript. LLG and AYW were responsible for revising the manuscript. ZYL performed the data collection. ZYL and JJZ performed the statistical analysis under supervision of AYW. All the authors reviewed and approved the final manuscript.

\section{Ethics approval and consent to participate}

Ethical approval was received from the Ethic Committee of School of Nursing, Sun Yat-sen University and the Third Affiliated Hospital of Sun Yat-sen University. All mothers were assured that their data would be kept confidential, that their participation was voluntary and that they could withdraw from the study at any time. They were informed of the purpose and the procedure of the study and all mothers gave written consent before inclusion.

Consent for publication

Not applicable.

\section{Competing interests}

Alex Wang is a member of the editorial board (Associate Editor) of BMC Pregnancy and Childbirth.

\section{Publisher's Note}

Springer Nature remains neutral with regard to jurisdictional claims in published maps and institutional affiliations.

\section{Author details}

${ }^{1}$ Guangdong Provincial Hospital of Chinese Medicine, The Second Affiliated Hospital of Guangzhou University of Chinese Medicine, Guangzhou, China. ${ }^{2}$ School of Nursing, Sun Yat-sen University, 74\#, Zhongshan Road II, Guangzhou 510089, China. ${ }^{3}$ Faculty of Health, University of Technology Sydney, Sydney, New South Wales, Australia. 
Received: 11 October 2018 Accepted: 31 March 2019 Published online: 18 April 2019

\section{References}

1. International Diabetes Federation. IDF Diabetes Atlas 8th edition. 2017 https://www.idf.org/our-activities/advocacy-awareness/resources-and-tools/ 134:idf-diabetes-atlas-8th-edition.html. Accessed 6 Apr 2018.

2. Bellamy L, Casas JP, Hingorani AD, Williams D. Type 2 diabetes mellitus after gestational diabetes: a systematic review and meta-analysis. Lancet. 2009; 373(9677):1773-9. https://doi.org/10.1016/S0140-6736(09)60731-5.

3. Kim C, Newton KM, Knopp RH. Gestational diabetes and the incidence of type 2 diabetes: a systematic review. Diabetes Care. 2002;25(10):1862-8. https://doi.org/10.2337/diacare.25.10.1862.

4. Zhu WW, Yang HX, Wang C, Su RN, Feng H, Kapu A. High prevalence of gestational diabetes mellitus in Beijing: effect of maternal birth weight and other risk factors. Chin Med J. 2017;130(9):1019-25. https://doi.org/10.4103/0366-6999.204930.

5. Guo J, Chen JL, Whittemore R, Whitaker E. Postpartum lifestyle interventions to prevent type 2 diabetes among women with history of gestational diabetes: a systematic review of randomized clinical trials. J Women's Health. 2016;25(1):38-49. https://doi.org/10.1089/jwh.2015.5262.

6. Pan XR, Li GW, Hu YH, Wang JX, Yang WY, An ZX, et al. Effects of diet and exercise in preventing NIDDM in people with impaired glucose tolerance the Da Qing IGT and diabetes study. Diabetes Care. 1997;20(4):537-44. https://doi.org/10.2337/diacare.20.4.537.

7. Saaristo T, Moilanen L, Korpi-Hyövälti E, Vanhala M, Saltevo J, Niskanen L, et al. Lifestyle intervention for prevention of type 2 diabetes in primary health care: one-year follow-up of the Finnish National Diabetes Prevention Program (FIN-D2D). Diabetes Care. 2010;33(10):2146-51. https://doi.org/10.2337/dc10-0410.

8. American Diabetes Association. Standards of medical care in diabetes 2017. Diabetes Care. 2017:40(Suppl 1):1-142.

9. Obstetrics and Gynaecology Department of the Chinese Medical Association, Pregnancy with Diabetes Group of the Perinatal Division among Chinese Medical Association. Clinical guideline for diagnosis and treatment of pregnancy with diabetes. Chin J Obstet Gynaecol. 2014;8(49): 489-98 (in Chinese)

10. Chang Y, Chen X, Cui HY, Zhang ZK, Cheng L. Follow-up of postpartum women with gestational diabetes mellitus (GDM). Diabetes Res Clin Pr. 2014;106(2):236-40. https://doi.org/10.1016/j.diabres.2014.08.020.

11. Kugishima Y, Yasuhi I, Yamashita H, Fukuda M, Kuzume A, Sugimi S, et al. Risk factors associated with abnormal glucose tolerance in the early postpartum period among Japanese women with gestational diabetes. Int J Gynecol Obstet. 2015;129(1):42-5. https://doi.org/10.1016/j.ijgo.2014.09.030.

12. Sterne $V L$, Logan $T$, Palmer MA. Factors affecting attendance at postpartum diabetes screening in women with gestational diabetes mellitus. Pract Dia Int. 2011;28(2):64-8a. https://doi.org/10.1002/pdi.1559.

13. Didarloo A, Nabilou B, Khalkhali HR. Psychosocial predictors of breast selfexamination behavior among female students: an application of the health belief model using logistic regression. BMC Public Health. 2017;17(1):1-8. https://doi.org/10.1186/s12889-017-4880-9.

14. Hajian-Tilaki K, Auladi S. Health belief model and practice of breast selfexamination and breast cancer screening in Iranian women. Breast Cancer. 2014:21(4):429-34. https://doi.org/10.1007/s12282-012-0409-3.

15. VanDyke SD, Shell MD. Health beliefs and breast cancer screening in rural Appalachia: an evaluation of the health belief model. J Rural Health. 2017; 33(4):350-60. https://doi.org/10.1111/jrh.12204.

16. Champion VL, Skinner CS. The health belief model. In: Glanz K, Rimer BK, Viswanath K, editors. Health behavior and health education: theory, research and practice. 4th ed. San Francisco: Jossey-Bass; 2008. p. 45-65.

17. Marmarà D, Marmarà V, Hubbard G. Health beliefs, illness perceptions and determinants of breast screening uptake in Malta: a cross-sectional survey. BMC Public Health. 2017:17(1):416. https://doi.org/10.1186/s12889-017-4324-6.

18. Eggleston EM, LeCates RF, Zhang F, Wharam JF, Ross-Degnan D, Oken E. Variation in postpartum glycemic screening in women with a history of gestational diabetes mellitus. Obstet Gynecol. 2016;128(1):159-67. https:// doi.org/10.1097/AOG.0000000000001467.

19. Lawrence JM, Black MH, Hsu JW, Chen WS, Sacks DA. Prevalence and timing of postpartum glucose testing and sustained glucose dysregulation after gestational diabetes mellitus. Diabetes Care. 2010;33(3):569-76. https://doi. org/10.2337/dc09-2095.

20. Suan MAM. Return for postpartum oral glucose tolerance test following gestational diabetes mellitus. Asia-Pac J Public He. 2015;27(6):601-9. https:// doi.org/10.1177/1010539515588943.

21. Hunt KJ, Conway DL. Who returns for postpartum glucose screening following gestational diabetes mellitus? Am J Obstet Gynaecol. 2008;198(4): 404e1-6. https://doi.org/10.1016/j.ajog.2007.09.015.

22. Guangzhou Bureau Of Statistics: Census assembly, the sixth census in Guangzhou. 2015. http://www.gzstats.gov.cn/gzstats/pchb_cydc/201704/ da6de855066f41e7bd832c159c11f3ff.shtml. Accessed 27 Sept 2018.

23. Zhu WW, Yang HX, Wei YM, Yan J, Wang ZL, Li XL, et al. Evaluation of the value of fasting plasma glucose in the first prenatal visit to diagnose gestational diabetes mellitus in China. Diabetes Care. 2013;36(3):586-90. https://doi.org/10.2337/dc12-1157.

24. Champion VL. Instrument development for health belief model constructs. Adv Nurs Sci. 1984;6(3):73-85. https://doi.org/10.1097/00012272-198404000-00011.

25. Champion VL. Instrument refinement for breast cancer screening behaviors. Nurs Res. 1993;42(3):139-43.

26. Wen ZY, You LM, Tan JL, Chen XY, Liang WP, Qin HY. Analysis of monitoring compliance and influencing factors of liver cancer high-risk group with family history. Nurs J Chin PLA. 2005;22(9):28-30 (in Chinese).

27. Liu ZY. Glucose screening within 6-month postpartum based on health belief among women with a history of gestational diabetes mellitus. Guangzhou: School of Nursing, Sun Yat-sen University; 2018. (in Chinese)

28. World Health Organization. Definition, diagnosis and classification of diabetes mellitus and its complications. 2nd ed. Geneva: World Health Organization; 1999.

29. Shiomi H, Nakagawa Y, Morimoto T, Furukawa Y, Nakano A, Shirai S, et al. Association of onset to balloon and door to balloon time with long term clinical outcome in patients with ST elevation acute myocardial infarction having primary percutaneous coronary intervention: observational study. BMJ. 2012;344(3):e3257. https://doi.org/10.1136/bmj.e3257.

30. Survey Office of the National Bureau of Statistics in Guangdong, 2018 Statistical bulletin for Guangzhou's national economic and social development in 2017. Retrieved April 9, 2019.from http://gjdc.gd.gov.cn/ ggl/201803/t20180302_150547.html

31. Cho GJ, An JJ, Choi SJ, Oh SY, Kwon HS, Hong SC, et al. Postpartum glucose testing rates following gestational diabetes mellitus and factors affecting testing non-compliance from four tertiary centres in Korea. J Korean Med Sci. 2015;30(12):1841-6. https://doi.org/10.3346/jkms.2015.30. 12.1841 .

32. National Health and Family Planning Commission of People's Republic of China. Management methods and norms of maternal and perinatal health care. 2011. http://www.gov.cn/gzdt/2011-07/08/content_1902348.htm. Accessed 11 Dec 2017.

33. Middleton P, Crowther CA. Reminder systems for women with previous gestational diabetes mellitus to increase uptake of testing for type 2 diabetes or impaired glucose tolerance (review). Cochrane Database Syst Rev. 2014;3:CD009578. https://doi.org/10.1002/14651858. cd009578.pub2.

34. Blatt AJ, Nakamoto JM, Kaufman HW. Gaps in diabetes screening during pregnancy and postpartum. Obstet Gynecol. 2011;117(1):61-8. https://doi. org/10.1097/AOG.0b013e3181fe424b.

35. Ferrara A, Peng T, Kim C. Trends in postpartum diabetes screening and subsequent diabetes and impaired fasting glucose among women with histories of gestational diabetes mellitus: a report from the translating research into action for diabetes (TRIAD) study. Diabetes Care. 2009; 32(2):269-74. https://doi.org/10.2337/dc08-1184.

36. Weinert LS, Mastella LS, Oppermann MLR, Silveiro SP, Pinto Guimaraes LSP, Reichelt AJ. Postpartum glucose tolerance status 6 to 12 weeks after gestational diabetes mellitus: a Brazilian cohort. Arq Bras Endocrinol Metab. 2014;58(2):197-204 https://doi.org/10.1590/0004-2730000003069.

37. Bennett WL, Ennen CS, Carrese JA, Hill-Briggs F, Levine DM, Nicholson WK et al. Barriers to and facilitators of postpartum follow-up care in women with recent gestational diabetes mellitus: a qualitative study. J Women's Health. 2011;20(2):239-45. https://doi.org/10.1089/jwh.2010.2233.

38. Katapodi MC, Lee KA, Facione NC, Dodd MJ. Predictors of perceived breast cancer risk and the relation between perceived risk and breast cancer screening: a meta-analytic review. Prev Med. 2004;38(4):388-402. https://doi. org/10.1016/j.ypmed.2003.11.012. 
39. Morrison MK, Lowe JM, Collins CE. Perceived risk of type 2 diabetes in Australian women with a recent history of gestational diabetes mellitus. Diabetic Med. 2010;27(8):882-6. https://doi.org/10.1111/j. 1464-5491.2010.03032.x.

40. Ma XY, Shi BJ, Fan J, Bao XF, Shen J, Zhu ZF, et al. Diabetic patients' misunderstanding on insulin therapy and it's effective nursing strategy. Nurs J Chin PLA. 2011;28(9B):35-8 (in Chinese).

41. Ding JR, Zhou YW, Dong HQ, Liu CL. Glucose follow-up survey of gestational diabetes mellitus in postpartum. Chin J Birth Health Heredity. 2010;18(02):63-4 (in Chinese).

\section{Ready to submit your research? Choose BMC and benefit from:}

- fast, convenient online submission

- thorough peer review by experienced researchers in your field

- rapid publication on acceptance

- support for research data, including large and complex data types

- gold Open Access which fosters wider collaboration and increased citations

- maximum visibility for your research: over $100 \mathrm{M}$ website views per year

At $\mathrm{BMC}$, research is always in progress.

Learn more biomedcentral.com/submissions 